Emilio Henriot

\title{
Don Juan o la Vida Vengadora
}

(Trad. para Alenea)

间国 IRSO de Molina, Molière, Byron, Mérimée y todos los que hasta aqui se han ocupado en Don Juan, el inmortal seductor de Elvira, me parecen haberse cuidado generalmente más de la moral que de la verdad: después de haber descrito su vida de escándalos y de crimenes, han creido deber colocar su obra con un gran ejemplo, y. para hacerla más conmovedora. le agregaron, como última pincelada del retrato y del drama, unos, un castigo espantable, otros, un arrepentimiento demasiado fácil. He aqui, pecadores, lo que os espera, parecen advertir al lector ligero estos moralistas intransigentes, mostrándoles al monstruo encantador que el Comendador castiga o que, espantado por la idea de la muerte próxima, se convierte in exfremis para asegurar. por algunos dias de apresurada contrición, su eterna bienaventuranza.

Es esto, a mi parecer, si no incurrir en una falta de psicología pues la composición del Don Juan literario no está exenta de ella, a lo menos subordinar en exceso a la necesidad de edificación. una pintura más humana de la vida; en todo caso, romper inútilmente la continuidad del carácier. más constante de lo que logra suponerse en un héroe tan locamente desinteresado. La experiencia nos demuestra, en efecto. que no siempre son los forajidos quienes vienen a ser castigados en el último aclo. 
en razón de que, lan dramática como pueda serlo. la vida jamás está reglada como una tragedia clásica. Aun el desenlance no es siempre inmediato en ella, y su drama nada tiene de teatral: es una tragedia que continúa.

Tal es la razón porque deseo referir aqui el verdadero castigo de Don Juan.

No es exaclo que el Comendador, a la hora de la cena fatal, haya tocado con su mano helada la mano del héroe. Tcnía, ciertamente, la intención de hacerlo: pero no lo hizo, porque este. Comendador era sensible a la braveza, y viendo a Don Juan cómo le miraba sin temblar, a pesar de su lemible apariencia y de oportunidad tan solemne, en el momento en que iba a anonadarle. sintió desperlarse en él sủbilamente cierta consideración hacia este hombre realmente valeroso.

Como el hermoso don Juan continuara observando al Comendador con su fuerte mirada inalterable, con una ligera sonrisa en los labios. con ese aire atento del hombre habiluado a las cosas extrañas, a la estatua de piedra le dijo:

-Don Juan, eres valiente, pero ¿me estrecharias la mano?

- No puedo, replicó Don Juan, rehusar con decencia la mano de un gentilhombre con quien tuve el honor de cruzar mi espada y a quien tuve el seniimiento de matar. si os acordáis. en un combate por demás leal.

Dijo estas palabras con entonación muy cortés. cuya amabilidad no hacía, sin embargo. sino subrayar aún con mayor delicadeza la tranquila ironia. Aun mantenia exlendida su hermosa mano.

- Soy yo quien ha de evitártelo, dijo lentamente el Comendador. manteniendo los brazos cruzados y sin extender la mano hacia la de su adversario. Estaba encargado de castigarte y de vengar tu odiosa perversidad: pero tengo la libertad de escoger mi venganza. Vive, pues. Sin embargo, no te consideres absuelto: vive sólo hasta la vejez: lú mismo serás quien ha de castigarte.

Y ahora fué al Comendador a quien tocó sonreir. Después desapareció sin dejar rastro. como fantasma que era. Don Juan. 
sobrecogido un momento, se pasó las manos por los ojos, como para arrancar la imagen importuna de un sueño, y alzó imperceptiblemente las espaldas, con el gesto que le era habilual.

En seguida, como no tuviera hambre y no estuviera en ánimo para cenar solo, despreciando la merienda que había hecho preparar para el hombre de piedra. fué a buscar a Zerlina. que le esperaba como todas las lardes, desde hacia diez años, los mismos que la lenia abandonada a sus remordimientos: y se presentó ante ella como si acabara de abandonarla la vispera.

Fué. por lo demás, muy bien recibido, no sin algunas lägrimas apasionadas, que agregaron mayor placer al encuentro. Zerlina era de esos seres ingenuos que fundan la felicidad en no experimenlar cambio alguno y en permanecer eternamente fieles a un ideal de perfección que se forjaron de una vez para siempre, por lo demás, sin saber acaso si su fidelidad no es sino la prueba de su ineplitud para crearse ofros. Formaba parte del ideal de Zerlina el permanecer inmulablemente-semejante a si misma; tal es la razón porque pareció a Don Juan que esta persona tan constante era la más vana. La vida, deslizándose. parecía no haberla tocado, y esla primera impresión fué agradable a su amante: al conlacto de un corazón tan fiel. se sintió rejuvenecido y vuelto tal como era por los años ya lejanos de su primer amor por Zerlina. Sin embargo, por una inclinación nalural a la joven cuya sensibilidad hallaba delicioso recorrer paso a paso el mismo camino con minuciosa exactitud y rememorar ardorosamente, a cualquier propósito, expuesta al peligro de parecer enfadosa recordándole historias que tenía él enteramente olvidadas, comenzó Don Juan a advertir que Zerlina era moda pasada, que nada habia aprendido después que él dejó de amarla, y que si se prestaba con tan amable facilidad a todas las fantasias de su nueva ternura, no acariciaba entre sus brazos sino el recuerdo del hombre que antes conociera y que él no era ya. Se produjo muy pronto en Don Juan el extraño sentimiento de que Zerlina le era en cierta manera infiel con él mismo; y cansado de tales complicaciones, poco inquieto, por lo demás: por desentrañar con cuál de estos dos 


\section{Don Juan o la Vida Vengadora}

Don Juanes se forjaba Zerlina la delicạda ilusión de engañar al otro, dejó en el acto de verla, definitivamente ahora, y sin esperanza alguna de volver.

No era tal vez Don Juan un hombre muy moral; pero es dificil negar que fuera extremadamente inteligente. Su ingenio, en los buenos tiempos de su carrera, le inclinó siempre a buscar en la experiencia inmediala un sentimiento de que pudiera aprovechar ocasionalmente, en el ejercicio cotidiano del culto de su felicidad personal, al que, desde la adolescencia, habia consagrado su vida y sus andanzas. Este relorno desgraciado para Zerlina le disuadió de exponerse por más tiempo a dejarse llevar por el placer de seducir a sus antiguas conquistas; esta especie de vueltas sobre sí mismo no le eran de provecho: confusamenle se daba cuenta de ello. Por otra parte, los últimos escándalos de su vida, sus duelos, sus frases hirientes. sus éxilos. su lono de perpelua mofa y su impía bravạta con el Comendador, doblemente irrespetuosa, pues ya no se trataba de un vivo. sino de un muerto, y muerto por'él. habían terminado por Taligar notablemente a la opinión pública en lo que a él locaba. Concibió que la vida tal como creía que debiera continuar la suya, luego llegaría a serle imposible en España, y tomó el partido de visitar otros países.

Entonces fué cuando pasó a Francia, de cuyas mujeres quedó desde luego grandemente satisfecho: las halló diferentes a las españolas y de un carácler mejor dispuesto a armonizar con el suyo. Vió en algunas de ellas una disposición notable para distinguir con gran sutileza los menesteres del placer y los del sentimiento. a quienes se podia ofrecer o solicitar el uno sin el otro y que no se perturbaban mezclando el corazón en exigencias que no lograria satisfacer. La facilidad con que ellas respondian a sus deseos, sin que él estuviera obligado siquiera a probarles que los sentia, le pareció una excitante novedad. A una gran actividad del placer, a su espiritu de inventiva para provocarlo. unian ellas, por una folal indiferencia, en el fondo sin duda más aparente que real, sobre el valor del bien ofrecido, el ejercicio de una libertad nalural y una rara facilidad de expresión, que 
tornaba fina y delicada la conversación con ellas en los difíciles momentos que siguen al amor exento de lernura.

Fascinado quedó Don Juan al descubrir este nuevo aspecto: estas francesas le parecian realmente de su gusto: le agradaba pensar que las encontraba amables porque en el londo se le parecian, y porque. como él, no buscaban sino el placer. Este pensamiento, que en un principio le arrebató, no tardó en envenenar la fuente del placer que en ellas tomaba. Reflexionó entonces que no le agradaria jugar al ajedrez con un adversario en cuyo pensamiento pudiera leer como en un libro abierto, y que la partida apareceria para él enteramente privada de interés desde el instante en que ya no ofreciera nada de imprevisto.

Buscó entonces, entre las francesas, una mujer capaz de experimentar esos hermosos y complicados sentimientos que un tiempo tuvo la fortuna de sorprender en Doña Ana, y cuya gracia reflexiva, discreción y severa belleza llegaran a unirse a un vivo ardor sensual y a la pasión española.

Creyó encontrar lo que esperaba junto a la mujer de un consejero del Parlamento de Borgoña, joven, bien formada, de mucho ingenio y carācler, y cuya mirada prometia, en su contenido fuego, esa felicidad patética y durable de que tanto tiempo estuvo privado. La vió por primera vez en la iglesia: y de su piedad dedujo un argumento favorable a la idea que desde el primer instante se forjara respecto a ella. La conoció: fué recibido en su casa: encontró en ella compañia escogida. los más refinados modales, el tono muy libre, aunque elevado siempre; y cuando juzgó llegado el momento conveniente. comenzó a hacerla la corte conforme a las reglas establecidas.

Pienso que es inúlil extenderse acerca de la ciencia de Don Juan en estas materias y de su dominio en toda clase de entretenimientos, regalos, comidas, partidas de caza, relatos, lecfuras, espectáculos y encantadoras sesiones de música, en que èl no desdeñaba unir, atendiendo siempre a un fin de utilidad, el concurso oficioso al atractivo de su mérilo personal: es verdad que este guapo caballero poseía a fondo el arle ingenioso de seducir sin därse apariencias de seductor. y sabía cómo es 
Don Juan o la Vida Vengadora

necesario agradar aun antes de haber dejado sospechar que se lo deseaba.

Natutalmente, no ignoraba que cada corazón tienc su apropiado camino, que sólo a él conduce: y aun tan desviado como pudiera estarlo, poseía el mágico don de discernir muy pronto el cạmino del corazón que debía ganar. Fué asi cómo llegó a hacerse amable a la consejera y cómo adelantó rápidamente sus propósilos respecto a ella. en liempo más escaso que el que se habia fijado.

La consejera era joven, adornada de raro ingenio y muy honesta. La reputación de Don Juan, que aun la lileratura no habia hecho resonar por todas partes, no habia llegado a sus oidos: podria asegurarse que si hubiera sabido qué peligroso -seductor reparaba en ella, esta mujer prudente lo habria mirado con desconfianza, y tal vez no hubiera tenido para tal personaje una acogida tan favorable. Tales fueron las razones, que la dejaron sorprendida cuando Don Juan, juzgando oportuno el momento. descubrió bruscamente sus baterias y libró valientemente el asalto.

La consejera le agradeció con mucha fincza y confusión el no haberla considerado indigna de inspirar tan vivo interés a un hombre como él, lleno de mérito y virtudes. Se confesó sensible a sus promesas, en que nada veia que no fuera honroso para ella: pero tenia el pesar de no poder compensarle en manera alguna, por una sola razón, que a él podía parecerle ridícula, lo que no impedia que fuera igualmente poderosa: y era que ella eslaba locamente enamorada, y de su marido.

Aquella misma noche. Don Juan tomó el camino de Italia.

De Italia pasó a Grecia, y de alli, a tierras de turcos: visitó diversos bazares de Oriente: atravesó una parte de la China; se deluvo entre los moscovitas; volvió por Alemania y los paises del Norte.

No tengo el propósito de consignar aqui el detalle de sus 
aventuras y las circunstancias que las hicièron pintorescas o trágicas, A pesar de la diversidad de tierras, de lo extraño de los sucesos y lo amable de sus relaciones, facilitadas por la bolsa repleta y la audacia del héroc, el único punto digno de memoria en todos eslos viajes es que el señor Don Juan no obluvo de ellos sino la, impresión de un largo y monótono fastidio, porque, aunque renovara el personal de sus experiencias y los paisajes que las decoraban, su curiosidad no se renovaba ya.

Asi conoció inglesas pasivas, alemanas glotonas, orientales resignadas. Tuvo gran número de mujeres, y la lisla se alargaba siempre. Unas mezclaban el amor a la vanidad, pero cesaba de preocuparlas desde que se veian libres de testigos que admiraran su triunfo, sin rivales a quienes desesperar o humillar. Otras no buscaban sino la distracción de la intriga. Algunas amaban verdaderamente, con toda el alma; pero en ellas la voluptuosidad resultaba harto mediana: lo que ante todo en su amante las interesaba era el pretexto de amar: no estaban enamoradas sino del amor. Otras, por fin, dotadas de sentidos más exigentes, no mezclaban ninguna delicadeza al placer de salisfacerlos. Con éstas, el único placer posible era un placer mudo, inmediatamente seguido de la indiferencia. Las habia que se abandonaban cerrando los ojos y que gemian como palomas: cedian al placer y parecian encerrar un secreto en el fondo de si mismas: pero al recobrarse, ya no conservaban tal apariencia.

La mayor parte sólo pensaban en su propia dicha, y jamás en procurarla: muchas veces tuvo Don Juan la impresión de que, entre los brazos que le estrechaban, ocupaba el lugar de otro. Excitado por el desdén, nunca olvidaba, antes de despedirse, dejar entender que no se le habia engañado. Como siempre acompañaba lo que decía con una sonrisa extremadamente fina. que escondia acaso con delicado pudor la herida de un corazón ensombrecido, adquịió una extraordinaria repulación de malignidad.

De tal suerte, arrastrado siempre por el sincero deseo de quedar enteramente subyugado - y no habria llegado a serlo sino por una crialura que hubiera comprendido que este hombre era 
sobre fodas las cosas un desgraciado a quien hubiera sido preciso consolar,-Don Juan no conoció jamás la suerte de ser condolido, y quiso la desgracia que, andando el tiempo, cobrara, también él. la costumbre de no tomar en cuenta sino su propio placer. Lo que le defendia de la depravación, lo que. tan libertino como hubiera llegado a ser. tan dolado de inventiva y del peligroso poder de imaginar, es el haberse dado cuenta muy pronto de que el circulo del placer es limitado y el placer. en si mismo, corto: el haber comprendido que todo el atraclivo del amor está más en el deseo que en el instante rápido que lo satisface: que el hombre mejor dolado para el amor puede alimentar con energia las ilusiones del apetito, acompañarlas de brillantes promesas, nutrirlas de locas ambiciones; pero, que. a pesar de todo. las más vivas se extinguen demasiado pronto. en cuanto la naturaleza se siente harta; y llega a estarlo muy luego: y que el animal no está satisfecho :ino a costa de inauditos engaños.

Los tiempos se habian consumado.

En sus agoladoras rebuscas. Don Juan advirtió por fin que le restaban más recuerdos que esperanzas. Pero sus recuerdos carecian de rostro. Había dejado de llevar su lista al dia: no experimentaba ningún placer releyéndola: la vanidad misma habia llegado a serle totalmente indiferente. Es más: cuando lograba posar una mirada distraida por esos millares de nombres. quedaba desagradablemente sorprendido porque no lograba colocar frente a ellos sino el de un héroe, siempre el mismo: el suyo. Zerlina, Don Juan; Elvira, Don Juan: Doña Ana, Don Juan: Mariana, Don Juan: Clorinda, Don Juan: Violante, Don Juan: Juliela, Isabel, Clara, Maria, Antonia, Faustina. Eleonora, Don Juan, Don Juan, Don Juan, Don Juan... iQué comedia tan poco variadal ¡Qué pobreza de comparsas! IQué monotonia en esta obligada reducción de problemas a un denominador común único! ‘Un solo héroe para tantas heroínas! Uno solo, siempre el mismo. Tal idea, cuando se le venia a la cabeza, hacia bostezar a Don Juan irremediablemente. Se hallaba siempre extremadamente uno mismo. El mismo y solo. Solo. 
Se hallaba solo, en efecto. Sganarelle habia muerto tiempo atrás. El pobre criado no representaba una compañia harto apreciable; pero, en fin, a pesar de sus reconvenciones, sus quejas, sus fastidiosos consejos, era alguien con quien se podia hablar, un pretexlo para oir el sonido de su propia voz. Muerto Sganarelle, Don Juan no habló ya. Se vió aún más solo. Entonces, arrasirado por una fuerza incierla, volvió a tomar el camino de España.

Cuando hubo puesto los pies en su suclo natal, en Sevilla, dudó del acierto de haber deseado ver nuevamente su patria. No se sentia inclinado a volver a su palacio: sabia que alli nada hallaria apropiado para distraerle. Se púso a caminar hacia adelante, al azar, el corazón vacio y el espíritu indiferente.

Era una suave noche de primavera, polvorienta y seca, llena de fragantes olores: el mismo aire polvoroso sentaba bien; Don Juan reparó en el poder de reconstrucción del perfume sobre la memoria. Esta sensación agradable le comunicó pronto una ligera alegría; decidió continuar vagando para no perder nada de este momento tan dichoso.

Su paseo le llevó hasta las murallas, desde donde la vista se extiende sobre la campiña sevillana, vaporosa y nítida. Cuando examinaba ese horizonte desnudo, que repentinamente volvia a encontrar infacto, vió una niña qua permanecía sentada sobre el muro, dedicada gravemente a comer uvas, sosteniendo el racimo al extremo del brazo, por sobre ella; mordisqueaba además, como un cabritillo, vuelta la cabeza, alguna rama demasiado alta para ella, bajo los parrales.

A Don Juan le pareció hermoso el cuadro, y se aproximó. atraído por el juego de la muchachita. Más próxima, parecia menos nína: iba vesfida de harapos vistosos y sórdidos; los brazos desnudos. macizos y de hermosas formas, El cuello extendido recortaba sobre el cielo puro una línea perfecta, de 
medalla, y luego, la garganta. llena, no era la de una niña. Sus piernas sucias estaban también desnudas, sus musculosos pies cubiertos de polvo oscilaban en el vacio, sobre el suelo. Pero la muchachita no prestaba ninguna atención al caballero que la observaba sonriendo. parado delante de ella con las manos en las caderas. Sólo cuando hubo concluido con el racimo. volvió hacia él la cabeza, entornó los ojos y riendo. le arrojó la película de la última uva a la cara. La frescura del hollejo chupado azotó la sangre viva del hombre, y como la niña se hubiera sentado de un salto sobre las piernas. la cogió de ambos puños. Ella no volvia los ojos: no hizo ninguna resistencia ni mostró temor alguno.

- He aquí una pcqueña desvergonzada, se dijo Don Juan. clavando la mirada en sus ojos.

Reteniéndola aún por las manos, la atrajo hacia él. para besarla en la cara, en cuanlo bajara esos ojos tan claros, que lo ofendian. Sin embargo. como no los desviara todavia, decidió abrazarla. Entonces ella volvió bruscamente la cabeza. y los labios del hombre no lograron rozar sino un bucle de los cabellos mal anudados tras de la oreja. Don Juan. sorprendido, retrocedió para ver mejor el rustro joven y obstinado.

- ¿No me quieres? ¿Por qué?

La pequeña movió la cabeza.

- ¿No? Vamos, no seas tonta. Y por de pronto. ¿cómo te llamas?

-Excepción, respondió ella.

- Todo un programa, replicó riendo Don Juan. Pero ¿tú sabes bien quién soy yo?

Excepción levantó los hombros. Seguro de si mismo. Don Juan lanzó el gran argumento.

- Me llaman Don Juan.

Probablemente la niña no habia oido hablar jamás de tan grande hombre. pues el nombre no hizo sobre ella mayor efecto que el vuestro o el mio.

- Es singular, se dijo Don Juan. Esto no vale un comino. $y$ me pone rabioso. 
Permaneció unos instantes contemplando la figura infantil y audaz, Con los ojos clavados en él, ella, realmente, no tenia ningún temor. Su carne joven, que aparecia dura a la mirada, brillaba bajo la suciedad, como una flor en el estercolero. Don Juan se sintió mordido, en el fondo de sí mismo, por su demonio. Después, temblando un poco, del solo deseo, le dijo en voz baja.

- ¿No te agrado yo?

Excepción le miraba tranquilamenle.

-No, dijo por fin; eres demasiado viejo.

Don Juan soltó las dos manos y dejó escapar a la muchacha. Alejándose, restregaba uno contra otro sus puños doloridos y no volvió la cabeza.

Fué algunos días después cuando Don Juan encontró a Elvira.

No la reconoció de pronto. Sólo vió a la vuelta de una callejuela. una mujer envuelta en un largo manto, que caminaba delanle de él, calzada con eleganles zuecos de plata. Seducido por la delgadez del tobillo, apresuró el paso; después, volviéndose enteramente, la miró a la cara, lanzando una exclamación.

Era una mujer vieja, amarillenta y arrugada, una mujer concluida, la que tenía ante si. Pero en esta cara marchita los ojos se habian conservado exactamente iguales y era aún los ojos. los magníicos ojos de Elvira. Ante su fuego, que no habia disminuído. Don Juan quedó suspenso. Un extraño sentimiento se animaba en él; y por primera vez en su vida, en pecado de corledad delante de una mujer, no sabía qué decir. No pudo sino pronunciar su nombre.

-IElvira!

Elvira se puso a reir inmediatamente y sacudió la cabeza.

- IUna sombra! INo es sino una sombral decía, riendo siempre.

Y con la mano, como se aleja un mosquito de la cara, hacía el ademán de ahuyentar un fantasma. 
- Una sombra no. Elvira; creedme, murmuraba humildemente Don Juan. Un hombre desgraciado y poco orgulloso de si mismo, que vuelve a ti para siempre; Don Juan, el Don Juan vuestro, Elvira.

La anciana reía a más y mejor.

- ISombra, déjame! Estoy enamorada y tú pierdes tu tiempo. No le pareces a aquel que yo amo, y el que yo amo murió hace mil años. No. no: tú no eres Don Juan, sombra vil, ¡Don Juan era más hermoso que túl Mira, y observa si te le pareces.

Y diciendo esto. tendió a Don Juan una minialura que llevaba al cuello. al extremo de una cadena de oro. Don Juan miró el retrato; era el suyo, el mismo que entregara a Elvira en los tiempos de sus buenos amores. Se reconoció en él, joven y lleno de fuerzas. Revolviendo la miniatura entre sus dedos, vió que llevaba al reverso un pequeño espejo de plata; donde pudo comparar el aspecto de lo que habia llegado a ser. Entonces recordó lo que le había dicho la niña en las murallas.

Elvira desapareció saltando sobre sus menudos zuecos de plata, balanceándose a derecha e izquierda. moviendo la cabeza y riendo siempre como una loca. Sólo en este momento comprendió Don Juan que estaba privada de razón.

Recordó éntonces lo que ella habia sido. y rememoró los grandes dias perdidos. Se dijo con amargura que Elvira habia tenido su corazón de veinte años, aquel que se da una vez y que nunca más podemos recobrar. Pensó que Elvira en medio de sus lágrimas le habia permanecido fiel. Reconoció que habia hecho mal a la única mujer que lo amara verdaderamente; y su corazón se apretó dolorosamente ante la idea de que antes de su demencia, Elvira debió juzgarle, y que aquella vez lué ante sus ojos menos hermoso de lo que un dia deseara serlo. Se dijo que el mayor crimen es haber engañado a quien nos ama, y que él habia malgaslado su vida. Terminó por concluir que el sentimiento de una vida perdida era el verdadero castigo que un hombre debia merecer por sus faltas, y su pensamiento voló hacia Elvira: .Por sobre los mares, bajo el cielo, en cualquier 
extremo de la fierra adonde vaya, en cualquier lugar, Elvira; o bien muerto, más allá de la tumba, desde lo profundo de los infiernos o de los cielos, elernamente en mi corazón. de hoy para siempre, alimentaré mi desesperación con tu recuerdo, oh. tú, que fuiste la primera en amarme, tú, a quien siempre desconocil.

Desde aquel dia, dudando de si mismo, menos seguro que nunca de haber estado en la razón, hizo el recuento de todas sus locuras, y comprendió que de ellas nada había guardado que pudiera consolarle en la vejez. Y el remordimiento no le abandonó ya, y le torturó tanto más cuanto no creia en Dios ni en el diablo, y no tenía fe, ni norma, ni moral cuyo rigor pudiera socorrerlo en su desamparo. Sabía sólo que había hecho mal, pues ya no había suerte de paz en su corazón. Y no lenia un hijo a quien formar, para hacer de él un hombre diferente. Estaba tan desesperado, que concluyó por recordar las extrañas palabras del Comendador, en las que jamás habia

pensado: .Vive, pues; pero no te consideres absuelto.

Razón tenia el Comendador. Don Juan comprendió que habria valido más quedar aniquilado en lo más vivo de su juventud heroica, incrédula y loca, antes que haber dudado jamás de si mismo. 